\title{
A PEDAGOGIA PLENA: UMA PROPOSTA UNITÁRIA DE FORMAÇÃO
}

\author{
Full pedagogy: a unitary training proposal \\ Pedagogía completa: una propuesta unitaria para la formación
}

Katia Augusta Curado Pinheiro Cordeiro da Silva*

https://doi.org/10.38117/2675-181X.formov2021.v3i1n5.114-130.

\section{Resumo}

O presente texto tem caráter de ensaio e visa apresentar elementos teóricos e metodológicos sobre a configuração do curso de Pedagogia Plena. O estudo se justifica pelo debate instaurado nesse momento em que a Base Nacional Comum Curricular - Resolução CNE/CP n 02/2019 - trouxe à tona os dilemas históricos sobre a identidade do curso de Pedagogia e evidenciou as contradições que permeiam a definição de políticas de formação em nosso país. Tendo como referência o estudo bibliográfico no campo educacional da Pedagogia, trabalhamos com a tese do curso de Pedagogia como uma graduação plena para superar, em sua estrutura, a separação entre bacharelado e licenciatura sem distinção de grau na formação. Em síntese, defendemos a identidade do pedagogo/a como profissional da educação capaz de analisar, compreender, lidar com as mudanças da e na vida social e suas implicações no sistema educacional, na escola; e defendemos também um curso de graduação plena que seja licenciatura e bacharelado, com projeto pedagógico próprio responsável pela formação de profissionais da educação professores/as e "especialistas" para a educação básica comprometidos com a educação crítica, com bases sólidas voltadas para a formação humana omnilateral, emancipadora

Palavras-chave: Pedagogia; Pedagogia plena; formação de professores. 


\begin{abstract}
This text is an essay and aims to present theoretical and methodological elements on the configuration of the Full Pedagogy course. The study is justified by the debate established at that time when the National Common Curricular Base - Resolution CNE / CP no 02/2019 - brought to light the historical dilemmas about the identity of the Pedagogy course and highlighted the contradictions that permeate the definition of education policies. formation in our country, with the movement of ideas marked by conceptions that deconstruct the field of teacher education. Taking as a reference the bibliographic study in the educational field of Pedagogy, we worked with the thesis of the Pedagogy course as a full graduation to overcome, in its structure, the separation between Bachelor and Licentiate degree without distinction of degree in formation. In summary, we defend the identity of the pedagogue / a as an education professional capable of analyzing, understanding, dealing with changes in and in social life and its implications in the educational system, at school; and we also defend a full graduation course that is a bachelor's and bachelor's degree, with its own pedagogical project responsible for the training of education professionals, teachers and "specialists" for basic education committed to critical education, with solid bases focused on human formation omnilateral, emancipatory.
\end{abstract}

Keywords: Pedagogy; full pedagogy; teacher training.

\title{
Resumen
}

Este texto tiene carácter ensayístico y tiene como objetivo presentar elementos teóricos y metodológicos sobre la configuración del Curso de Pedagogía Plena. El estudio se justifica por el debate establecido en este momento cuando la Base Curricular Nacional Común Resolución CNE/CP No 02/2019 - planteó los dilemas históricos sobre la identidad del curso de Pedagogía y evidenció las contradicciones que impregnan la definición de las políticas de formación en nuestro país. Teniendo como referencia el estudio bibliográfico en el ámbito educativo de la Pedagogía, trabajamos con la tesis del curso de Pedagogía como una graduación completa para superar, en su estructura, la separación entre licenciaturas y licenciaturas sin distinción de grado en formación. En resumen, defendemos la identidad del pedagogo como un profesional de la educación capaz de analizar, comprender, abordar los cambios de y en la vida social y sus implicaciones en el sistema educativo, en la escuela; y también abogamos por un curso completo de pregrado y licenciatura, con su propio proyecto pedagógico responsable de la formación de profesionales de la educación docentes y "especialistas" para la educación básica comprometidos con la educación crítica, con bases sólidas enfocadas en la formación humana omnilateral, emancipadora.

Palabras clave: Pedagogía; Pedagogía Completa; Formación del Profesorado. 


\section{Introdução}

As mudanças curriculares para o curso de Pedagogia fazem parte de uma ampla, longa e discutida reforma na organização dos cursos de graduação e na formação dos profissionais da educação no Brasil. Após a promulgação da Lei de Diretrizes e Bases da Educação Nacional - LDB - em dezembro de 1996 (BRASIL, 1996), a Secretaria de Ensino Superior do Ministério de Educação - Sesu/MEC -, por meio do Edital n. 4, de 4 de dezembro de 1997 (BRASIL, 1997), deu início ao processo de mudança curricular, solicitando às Instituições de Ensino Superior - IES - que enviassem propostas para a elaboração das Diretrizes Curriculares para os cursos de graduação. O curso de Pedagogia foi um dos últimos a ter suas Diretrizes Curriculares aprovadas, o que aconteceu por meio da Resolução nº 1, de 15 de maio de 2006, do Conselho Nacional de Educação - CNE.

Está em debate, novamente, as Diretrizes Curriculares Nacionais para o curso de Pedagogia, movimento que faz parte de um projeto reformador assumido e implementado pelo Conselho Nacional de Educação com uma proposta neoliberal-gerencialista. Tal debate traz à tona, mais uma vez, a discussão a respeito da identidade do curso e da sua finalidade profissionalizante, agora instituída como licenciatura. Em atual formulação legal, o curso de Pedagogia, graduação de nível superior no Brasil, é uma licenciatura destinada à formação de professores/as para a educação infantil e anos iniciais do ensino fundamental; professores/as para o ensino nos cursos de nível médio, na modalidade normal; professores/as para o ensino na educação profissional, área de serviços e apoio escolar; profissionais para as atividades de organização e gestão educacionais; e formação de profissionais para as atividades de produção e difusão do conhecimento científico e tecnológico do campo educacional. Constitui-se, portanto, em espaço acadêmico central do campo de conhecimento da educação no país e, sendo um curso de licenciatura destinado primordialmente à formação de professores/as para a educação infantil e anos iniciais do ensino fundamental.

Consideramos que a identidade do curso de Pedagogia é forjada em um contexto amplo no qual operam múltiplas determinações, a começar pelo projeto educativo hegemônico e os projetos contra-hegemônicos de nação e suas consequentes políticas educacionais. Assim, tais embates travados na sociedade civil, portanto no Estado integral (GRAMSCI, 2012) promovem, por meio dos sujeitos históricos, disputas que definem o marco epistemológico do curso de Pedagogia.

Neste artigo, apresentamos os resultados de um trabalho de estudo bibliográfico que buscou elementos da proposta de construção de um curso de Pedagogia Plena que 
deveria superar, em sua estrutura, a separação entre bacharelado e licenciatura sem distinção de grau na formação; e temos como objetivo apresentar elementos teóricos e metodológicos sobre a configuração desse curso.

\section{Elementos para um curso de graduação de Pedagogia Plena}

A defesa de um curso de graduação plena surge em 1998, no IX Encontro Nacional, em que a Associação Nacional pela Formação dos Profissionais da Educação - ANFOPE indica, pela primeira vez, sua proposta de Diretrizes Curriculares para todos os Cursos de Formação dos Profissionais da Educação, firmando os seguintes princípios: 1. Necessidade de pensar as Diretrizes da Pedagogia como parte indissolúvel e articuladas às Diretrizes Curriculares para todos os Cursos de Formação dos Profissionais da Educação; 2. Exigência de ampliação e democratização do debate, levando em conta a produção do movimento dos educadores e da ANFOPE nos últimos 15 anos, com posição contrária a qualquer processo que desconheça os caminhos construídos pelo movimento tanto do ponto de vista da forma, quanto do conteúdo das propostas; 3. As Diretrizes Curriculares não devem constituir-se "camisa de força" para as IES, mas explicitar áreas de formação que, nas particularidades dessas instituições, possam ser materializadas, levando-se em conta a Base Comum Nacional; 4. Esse processo não poderá significar o "enxugamento" das disciplinas teóricas dos currículos atuais dos cursos de graduação, sob pena de desqualificar a formação básica e enfatizar as práticas sem qualquer conteúdo de formação qualitativamente superior (ANFOPE, 1998). Tais discussões iniciais foram elementos propositivos para pensar um curso de Pedagogia de Graduação Plena.

No X Encontro Nacional da ANFOPE, em 2000, ao analisar as concepções presentes nos documentos legais - LDB (BRASIL, 1996) e Resolução n o 01/99 dos Institutos Superiores de Educação (BRASIL, 1999) - e as proposições que já se faziam presentes na área para a criação do bacharelado em Pedagogia, retoma a histórica discussão da entidade sobre o Curso de Pedagogia, reafirmando os princípios da base comum nacional, a docência como base da formação de todos os educadores e a defesa da autonomia universitária como condição para estimular as iniciativas curriculares nas IES (ANFOPE, 2000). Assim, a entidade aponta que

O Curso de Pedagogia é um curso de graduação plena, superando em sua estrutura a separação entre bacharelado e licenciatura presente nas demais áreas de formação de professores [...] tem permitido seu aprimoramento e aperfeiçoamento na direção de tomar a prática educativa e a educação como objeto de estudo na formação de profissionais para atuação na educação básica identificando, no 
trabalho pedagógico escolar e não escolar, elementos constitutivos da formação humana em sua dimensão omnilateral. (ANFOPE, 2000, p.20).

Mas o que significa um curso ser uma graduação plena? Em um primeiro momento pode parecer a contraposição à licenciatura curta, historicamente existente na história dos cursos de graduação para professores/as., mas aqui, o sentido é outro: trabalhamos e defendemos a tese que o curso de Pedagogia deve superar um dos principais dilemas: a dicotomia entre o bacharelado e a licenciatura; e formar o pedagogo/a para atuar em espaços escolares e não-escolares, na docência, na gestão e na produção e difusão do conhecimento do campo educacional. Assumir a ideia de Pedagogia Plena rompe com visões distorcidas e dicotômicas da interpretação da função do pedagogo/a e evita confusões com termos legais de Pedagogia integral/única.

Sabemos que a Pedagogia tem como objeto de estudo a educação em espaços escolares e não escolares. Dessa forma, um curso de graduação plena sendo licenciatura e bacharelado, com projeto pedagógico próprio, seria responsável pela formação de profissionais da educação professores/as e "especialistas" para a educação básica, sem fragmentar ou dissociar a formação e o trabalho ou mesmo agravar a divisão do trabalho na escola. Essa divisão do trabalho nas escolas se caracteriza, sobretudo, pela existência considerável da separação entre trabalho manual e trabalho técnico, entre o professor/a que realiza o processo pedagógico e o professor/a que pensa esse processo, os quais se distinguem dos profissionais docentes e não-docentes (orientadores, supervisores, coordenadores, entre outros); e se caracteriza, ainda, pela sua formação específica. Assim, a nossa defesa foi sempre pela base da docência que traria unicidade ao desempenho dos papeis, mas para além da base de identidade docência (que é discutida posteriormente neste artigo) defendemos uma formação única, na graduação plena de Pedagogia.

Marx e Engels (1992) entendem que a educação tem que abordar três aspectos importantes da constituição física e intelectual do ser humano: o primeiro é o aspecto do intelecto; a educação deve desenvolver o intelecto do ser de forma completa; o segundo é a educação para o desenvolvimento corporal através da ginastica, esportes etc.; e o terceiro, a educação tecnológica, cujo aspecto está relacionado ao processo produtivo. Porém, na sociedade do capital, onde reina a divisão entre trabalho manual e intelectual, tais aspectos não são engendrados no seu conjunto porque essa divisão é um aspecto necessário da educação capitalista. No entanto, é valido lembrar e ressaltar que é também, mas não unicamente, por meio da educação que os indivíduos podem se libertar da dominação ideológica da classe dominante e formar grupos, partidos etc. para combater essa classe opressora e construir até mesmo o socialismo. 
Nesse sentido, a formação de pedagogos/as professores/as ou de pedagogos/as para espaços escolares e não escolares que tenha como centralidade o objeto educação necessita ser uma formação plena, única e integral, a fim de romper com o ciclo de divisão no trabalho. Para Brandão (2006, p. 9), a educação se trata de um conceito polissêmico que varia de acordo com tempos e espaços distintos, que se manifesta por modos de pensar e agir, uma vez que "ninguém escapa da educação [...] não há uma única forma nem um único modelo de educação; a escola não é o único lugar em que ela acontece e talvez nem seja o melhor; o ensino escolar não é a única prática e o professor profissional não é seu único praticante". Este é um elemento importante e, por isso mesmo, defendemos uma formação plena, una, única, referenciada no conceito de Pedagogia Plena contra uma redução teórico-conceitual da Pedagogia que, limitada a uma dimensão técnica e instrumental, coloca-se a atender aos interesses do mercado e dos processos educativos.

Temos, por princípio, que a formação inicial e continuada, marcada pelos aspectos objetivos e subjetivos que irão compor o sujeito pedagogo/a, é fundamental no trabalho pedagógico, assim como entendemos que é preciso uma formação que contemple as especificidades do trabalho no espaço escolar e não escolar. Entretanto, entendemos que a totalidade do objeto de estudo - a educação e o fenômeno identitário como a docência - é fundamental para a constituição de uma Pedagogia Plena que avance para além das dicotomias e polaridades caras ao mundo capital. Nesse sentido, passamos a apresentar alguns aspectos teórico-metodológicos para fundamentar o curso de Pedagogia Plena.

\section{O princípio da formação omnilateral}

A formação omnilateral em Marx e Engels (1992) apresenta-se como uma das categorias que destaca o trabalho enquanto princípio educativo, pois propõe a união de ensino e trabalho. Considerar o trabalho enquanto princípio educativo, na perspectiva marxista, pode parecer um tanto contraditório ao se observar o caráter negativo do trabalho enfatizado por Marx. No entanto, entender o princípio educativo do trabalho requer uma compreensão ampliada desta categoria para além do sentido histórico de trabalho alienado e fetichizado que assim se caracteriza sob o jugo do modo de produção capitalista. É preciso, ainda, compreender a dimensão dupla e contraditória que o trabalho assume neste contexto e que Marx bem destaca, afirmando que ao mesmo tempo em que o trabalho cria e humaniza, também aliena, degrada e subordina o homem. 
Segundo Frigotto (2005, p. 3), Marx sinaliza a dimensão educativa do trabalho mesmo quando esse trabalho se dá sob a negatividade das relações de classe existentes no capitalismo, pois Marx, ao analisar a relação dos homens entre si e com a natureza, destaca não apenas que os homens, para produzirem os meios de vida, transformam a natureza transformando também a si próprio, mas também que esta atividade prática do homem é ponto de partida na construção de sua consciência, da cultura e do conhecimento. Destacamos ainda que, na perspectiva dialética, é possível compreender o trabalho em sua propriedade educativa nas dimensões positiva e negativa que apresenta.

O trabalho é parte fundamental da ontologia do ser social. A aquisição da consciência se dá pelo trabalho, pela ação sobre a natureza. O trabalho, neste sentido, não é emprego, não é apenas uma forma histórica do trabalho em sociedade, ele é a atividade fundamental pela qual o ser humano se humaniza, se cria, se expande em conhecimento, se aperfeiçoa. O trabalho é a base estruturante de um novo tipo de ser, de uma nova concepção de história. (FRIGOTTO, 2005, p. 4).

Por este caráter contraditório do trabalho alienante e emancipador, fica evidente que para Marx é inaceitável qualquer formação a partir do modo de produção capitalista. Marx (2004), entretanto, destaca a necessidade de uma formação para os trabalhadores/as aliada ao trabalho como forma de superação deste sistema e não como realização plena do homem no sentido omnilateral que defende.

A formação omnilateral deve, necessariamente, superar a oposição entre formação intelectual e formação técnica. Para tanto, é preciso entender que a atividade prática é, além da possibilidade de adquirir experiência útil, a possibilidade de aplicar e criar o saber teórico; portanto, indispensável a esta formação. É possível uma formação omnilateral pela qual os sujeitos alcancem a compreensão sobre a totalidade do processo social do qual fazem parte. Qualquer formação que separe e/ou crie dicotomias entre o pensar e o fazer ser professor/a e ser especialista, entre outras divisões, manterá seu caráter unilateral, formando sujeitos parciais para atividades parciais. A formação omnilateral pressupõe mais do que a união; objetiva a formação plena de um novo homem, neste caso, específico de um pedagogo/a, na Pedagogia Plena.

A omnilateralidade, ao mesmo tempo em que requer outro projeto de sociedade que resgate a integralidade da atividade humana, é um dos elementos centrais para a superação da formação unilateral do homem. Portanto, a categoria de formação omnilateral afirma o trabalho como princípio educativo, pois não busca apenas a união entre ensino e trabalho, mas parte da perspectiva da emancipação humana e, tendo esta por horizonte, pressupõe a formação enquanto crítica real, buscando, assim, as condições para que se alcance a omnilateralidade na totalidade de uma nova sociedade. 
É neste sentido que trabalhar com o princípio da formação omnilateral se constitui elemento central para o curso de graduação de Pedagogia Plena, pois decorre dessa formação a perspectiva de unidade que indica elemento de superação não apenas da dicotomizada formação unilateral dos homens, como por exemplo em bacharelado e licenciatura, professor/a e especialista, pedagogo/a escolar e não escolar; mas é, sobretudo, a oportunidade do acesso omnilateral aos bens sociais e a um fazer pela práxis. Assim, Marx e Engels (1992) afirma seu entendimento do trabalho enquanto princípio educativo não na forma alienada como o trabalho se apresenta em sua dimensão histórica na sociedade capitalista, mas em sua dimensão ontológica, resgatando a união entre consciência e prática social, como crítica da forma atual em que o trabalho se apresenta e como possibilidade de ser realizado plenamente seu caráter ontocriativo.

A formação em Pedagogia Plena, tendo como princípio a formação omnilateral, pressupõe a unidade entre teoria e prática não apenas no local da formação, mas no próprio campo de trabalho. Pressupõe, ainda, a possibilidade da "manifestação plena e total de si mesmo, independente das ocupações específicas que cada indivíduo [...] [exerce]" (MANACORDA, 2010, p. 48). Somente a partir desta unidade entre formação intelectual e formação manual, aliada à prática social, é que se considera possível uma formação omnilateral, pela qual os sujeitos alcancem a compreensão sobre a totalidade do processo social do qual fazem parte. Neste sentido, Marx (2007, p. 107) afirma que, para o homem atingir efetivamente sua condição omnilateral, por um lado é necessário modificar as condições sociais para criar um novo sistema de ensino, e por outro, falta um sistema de ensino que contribua para a transformação das condições sociais. É essa tese que assumimos neste artigo/ensaio.

Partindo-se de uma concepção de educação que propõe uma formação omnilateral do sujeito, futuro pedagogo/a, percebemos, nesse contexto, uma proposta educacional radicalmente humanista e oposta à formação para o mercado de trabalho capitalista com suas divisões e fragmentações. Assim, conhecendo o campo de formação da Pedagogia, suas aspirações, projetos em disputa, suas limitações e seus problemas, esse modelo de formação humanista proporciona um ensino na unidade do ser pedagogo/a, estudioso/a do objeto da educação que tem a docência como base de identidade, mas podendo exercer, a partir da totalidade do ser pedagogo/a, diferentes funções que podem ser aprimoradas na formação continuada. Nesse sentido, tem-se uma formação menos ligada aos ditames do capital que insiste em formar um perfil que reduz o sujeito à materialidade da função, a objeto de domínio. A formação numa perspectiva omnilateral requer que os sujeitos se emancipem; entretanto, na formação ampla da sua humanidade, podem compreender e exercer as especificidades do campo de conhecimento. 


\section{A base comum nacional e a identidade da docência}

Neste ensaio, estamos aprofundando a questão da Pedagogia Plena por entendermos que tópicos como "base comum nacional", "identidade do curso de Pedagogia", "licenciatura e bacharelado", entre outros permanecem tanto tempo em discussão porque permeiam questões complexas de uma sociedade capitalista que esconde, em suas relações, tramas e poderes para a constituição de um projeto hegemônico que reverbere em estreita interação com as relações sócio produtivas, enfatizando o tecnicismo e a produtividade.

Quando assumimos a perspectiva de uma Pedagogia Plena, sendo ao mesmo tempo licenciatura e bacharelado sem se fragmentar em especializações e/ou percursos formativos, estamos assumindo uma lógica de formação que vise e tenha como objetivo o objeto educação na sua totalidade, com especificidades que também serão contempladas a partir e com uma visão unitária de realidade. Nesse sentido, o princípio de base comum nacional defendido pela Anfope se torna basilar.

O conceito de Base Comum Nacional (BCN) para todos os cursos de formação de professores busca definir eixos norteadores quanto à organização da proposta formativa, reafirmando a necessidade de se ter o trabalho docente como princípio educativo. Nesse sentido, muito diferente da Base Nacional Comum da Formação de Professores - BNCCFP (Resolução CNE/CP 2/2019), que fica circunscrita a uma padronização curricular referenciada em um conjunto de competências e habilidades ou seja, a um currículo a ser prescrito, o princípio da ANFOPE de BCN trabalha na perspectiva da unidade de um projeto de formação em que o termo "Base" é entendido como núcleo essencial da formação no que se refere ao diálogo com as áreas do conhecimento que subsidiaram a educação como: sociologia, psicologia, filosofia, história, economia, fundamentos epistemológicos/educação. O segundo termo "Comum" foi concebido como ponto de partida, referência e articulação curricular de uma formação comum para todos os profissionais da educação "intra e inter instância de formação" (V ENCONTRO NACIONAL DA CONARCFE/ANFOPE, 1990, p. 5).

Ter como referência uma Base Comum Nacional para compor o curso de Pedagogia Plena é uma indicação para que a estrutura organizativa desse curso possa superar as práticas curriculares que tradicionalmente dicotomizam teoria x prática; pensar $\mathrm{x}$ fazer; trabalho x estudo; pesquisa x ensino. Trata-se de uma política global e não apenas curricular capaz de contemplar o tripé: formação inicial; condições de trabalho, salário e 
carreira; e formação continuada como condição de melhoria da qualidade da educação básica na perspectiva de construir a política de profissionalização e valorização do magistério e um sistema nacional de formação dos profissionais da educação. Dessa forma, a concepção da BCN é a constituição de um projeto emancipador de concepção crítica, requerendo, para sua materialização, a construção de uma política no âmbito institucional que entendemos ter sido iniciada com a Resolução CNE/CP n 2/2015 e que, agora, foi golpeada pela iniciativa da nova composição do Conselho Nacional de Educação.

A Base Comum Nacional é um conjunto de eixos norteadores da organização curricular, entendidos como princípios orientadores das condições de formação que deveriam estar presentes nos processos formativos, propiciando a todos os estudantes e educadores formação inicial e formação continuada de modo que

A organização curricular dos cursos de formação dos profissionais da educação deverá orientar-se pelas seguintes diretrizes curriculares: * a formação para o humano, forma de manifestação da educação omnilateral dos homens; * a docência como base da formação profissional de todos aqueles que se dedicam ao estudo do trabalho pedagógico; * o trabalho pedagógico como foco formativo; * a sólida formação teórica em todas as atividades curriculares - nos conteúdos específicos a serem ensinados pela escola básica e nos conteúdos especificamente pedagógicos; * a ampla formação cultural; * a criação de experiências curriculares que permitam o contato dos alunos com a realidade da escola básica, desde o início do curso; * incorporação da pesquisa como princípio de formação; * a possibilidade de vivência, pelos alunos, de formas de gestão democrática; * desenvolvimento do compromisso social e político da docência; * a reflexão sobre a formação do professor e sobre suas condições de trabalho (ANFOPE, 1998, p. 35 ).

A proposta referenciada na Base Comum Nacional entende que o percurso da formação do professor/a deve ir em direção ao ser omnilateral, passando necessariamente pela reflexão da distinção entre o ser prático e o ser pensante, guiada pela necessidade da construção de homens iguais, com distintas capacidades que construirão, a partir da compreensão e direção do real, uma gestão consciente de todo o processo de produção, circulação e consumo das riquezas sociais. O eixo dessa formação é o trabalho pedagógico escolar e não escolar que tem na docência - compreendida como ato educativo intencional - o seu fundamento. É a ação docente o fulcro do processo formativo dos profissionais da educação, ponto de inflexão das demais ciências que dão o suporte conceitual e metodológico para a investigação e a intervenção nos múltiplos processos de formação humana. 
O curso de Pedagogia, a partir da Base Comum Nacional, também assumiria a "docência como base" que implica numa compreensão efetiva do trabalho educativo de forma ampla, mesmo sendo este trabalho de naturezas diversas. A "docência como base" para todos os profissionais da educação se refere, portanto, aos componentes comuns de formação desejáveis a todos aqueles que exercerão o trabalho educativo em ambientes escolares ou fora deles, mas sempre comprometido com a tarefa de socialização e de produção do conhecimento.

Em pesquisa realizada sobre o pedagogo/a em espaço não escolar, desenvolvida na Universidade de Brasília, ficou evidenciado, nas entrevistas, que a formação referenciada na docência, ou seja, na organização do trabalho pedagógico, contribui para a compreensão, elaboração, execução e avaliação de projetos educativos em espaços não escolares. Ao serem questionados/as sobre a importância da base docente e sua relevância na formação do pedagogo/a não docente, os entrevistados/as foram unânimes em atribuir a essa base alta significância nos conhecimentos práticos que proporcionam um melhor embasamento em suas atribuições não docentes. A partir de um curso com sólida e densa formação teórica, os entrevistados/as entendem que a parte diversificada da estrutura curricular do curso de Pedagogia garante aos seus formados/as conhecimentos específicos a cada área de atuação e, além disso, destacam que poderia haver um aprofundamento na implementação da formação continuada. A experiência docente em atribuições extraescolares, no entanto, é tida como algo dispensável já que não se trata de atribuições ligadas diretamente à escola.

Assim, estamos assumindo que o sentido da docência é ampliado e se articula à ideia de trabalho pedagógico a ser desenvolvido em espaços escolares e não escolares, em que

[...] tomados sob essa perspectiva o trabalho docente e a docência implicam uma articulação com o contexto mais amplo, com os processos pedagógicos e os espaços educativos em que se desenvolvem, assim como demandam a capacidade de reflexão crítica da realidade em que se situam. Com efeito, as práticas educativas definem-se e realizam-se mediadas pelas relações socioculturais, políticas e econômicas do contexto em que se constroem e reconstroem. (AGUIAR et al., 2006, p. 830).

Diante disso, o curso de Pedagogia Plena formará um profissional polivalente, assim como acontece com o curso de Medicina, Direito, Engenharia, entre outros. O título oportunizará aos egressos/as desenvolver profissionalmente várias atividades em espaços escolares e não escolares, com uma ampla visão do trabalho educativo consequente de uma formação densa e sólida. Portanto, ter na docência sua identidade profissional não 
significa reduzir a ação pedagógica à docência, mas incorporá-la como um determinante estrutural na compreensão e intervenção da e na práxis educativa, efetivando, com isto, uma concepção unitária de formação do pedagogo/a para atuar na educação escolar e nãoescolar.

\section{Trabalho pedagógico escolar e não escolar}

O trabalho é o princípio fundamental que caracteriza o homem como ser humano, pois é por meio da atividade de transformação da natureza que o sujeito transforma a si mesmo, constituindo o processo de humanização. Assim, o homem se constrói nas relações que estabelece na prática social, mediatizando, pelo trabalho, sua relação com a natureza, consigo mesmo e com os outros homens. Dessa forma, a atividade do trabalho é entendida como princípio fundamental para se entender o homem como ser humanizado. Não se pode ser plenamente humano se não se puder trabalhar, exercer atividade teórico/prática na sociedade.

A partir desta tese, tomamos o trabalho como princípio educativo, entendendo que este possui, então, no seu processo dinâmico, dois polos que se articulam contraditoriamente: a teoria e a prática; a concepção e a execução; o saber e o fazer; a negatividade e a positividade. Com efeito, o princípio do trabalho é apreendido como referencial teórico porque, dentro de uma pedagogia sócio-histórica de formação humana, explicita a compreensão da produção e manutenção da existência histórica do homem concreto. Nesse sentido, defendemos a necessidade dos aportes teórico-metodológicos que tomam o trabalho como princípio ontológico para a formação no curso de Pedagogia Plena. Tal orientação trará unidade a partir do trabalho escolar e não escolar, superando as recomendações reducionistas dos apelos pela construção dos saberes a partir de uma epistemologia da prática pela qual se tem uma formação frágil e neotecnicista e uma consequente ação medíocre em quaisquer campos em que os pedagogos/as atuarem, quer seja nos espaços escolares ou não escolares.

Tomar o trabalho escolar e não escolar centrado na docência reafirma o processo de reconstrução do movimento interdisciplinar nos cursos que podem articular os conhecimentos relativos ao trabalho pedagógico aos campos de outras ciências, de modo a formar profissionais de educação com novos perfis, capazes, por exemplo, de atuar com as novas tecnologias, com as diferentes mídias e linguagens, com a participação social, com o lazer, com programas de inclusão das culturas diversas, das pessoas com necessidades especiais e outras inúmeras possibilidades formativas que a vida social e 
produtiva demandar. Essa gama de possibilidades, bem como sua diversidade aberta pela prática social e produtiva, evidencia a necessidade de conhecimentos mais aprofundados e a hipótese de que a docência poderia ser o pré-requisito para dar o suporte necessário à efetiva atuação nos diferentes contextos, embora se possa admitir que a docência preceda à formação especializada (KUENZER; RODRIGUES, 2007), sendo uma formação sólida nas teorias, nos fundamentos e nas práticas pedagógicas que possam ser comuns nas diferentes frentes de atuação.

O pedagogo/a, ao encaminhar o processo educativo não escolar e/ou escolar, tem sua ação baseada na preocupação com a intencionalidade na organização da atividade educativa, com os encaminhamentos teórico-metodológicos para assegurar todas as dimensões à apropriação do conteúdo/informação, com vistas à superação do senso comum rumo a uma perspectiva de transformação e emancipação dos envolvidos nesse processo. Entendemos e assumimos a Pedagogia como campo de conhecimento da e para a prática educativa, compreendendo aqui práticas escolares e não escolares, e

[...] Portanto, entendemos que há uma ação docente intrínseca na prática educativa escolar e na não-escolar, é uma postura intencionalizada que possui suas nuances em função das especificidades das naturezas dos lócus de formação humana, porém a atividade docente é basilar (SÁ, 2000, p. 177).

\section{Possibilidades de estruturação do curso}

Diante do exposto, concordamos que há necessidade de serem questionadas concepções, teorias e práticas que reiteram propostas que marginalizam a Pedagogia enquanto um campo de conhecimento, com especificidades epistemológicas. Todavia, temos a clareza de que não basta mudar a estrutura curricular do curso a fim de resolver o problema histórico da formação do pedagogo. Entendemos a necessidade de fundamentar-se na proposta de um projeto político pedagógico e nesse sentido apontamos alguns elementos gerais para sintetizar o curso de Pedagogia Plena:

1- $\quad$ Os cursos de Pedagogia deveriam ser uma graduação plena que abarca licenciatura e bacharelado, com projeto pedagógico próprio responsável pela formação de profissionais da educação professores/as e "especialistas" para a educação básica, comprometidos com a educação crítica com bases sólidas e voltada para a formação humana omnilateral, emancipadora (ANFOPE, 2006)

2- $\quad$ Assumir que todo o trabalho do pedagogo/a no espaço escolar e não escolar é pedagógico em sua totalidade, e este se constitui a base da formação de todos 
os profissionais da educação. Portanto, a docência entendida como o trabalho pedagógico é a base da identidade do curso de Pedagogia no entendimento de que não é possível separar teoria e prática, pensar e fazer, conteúdo e forma no processo de formação profissional. (ANFOPE, 2006).

3- $\quad$ As diretrizes para o curso de Pedagogia propõem uma organização ampla e sugerem que os cursos contemplem três núcleos de estudos, a saber: i) núcleo de estudos básicos; ii) núcleo de aprofundamento e diversificação de estudos; e iii) núcleo de estudos integradores - Resolução n. 1, de 15 de maio de 2006 (BRASIL, 2006). Sugerem também que a articulação desses núcleos e do corpo de conhecimentos que lhes dá sustentação seja orientada pelos princípios de interdisciplinaridade; contextualização; democratização; pertinência e relevância social, ética e sensibilidade afetiva e estética.

4- $\quad$ O trabalho como princípio educativo deve percorrer todo o curso e ser entendido como eixo articulador de produção de conhecimento socioeducacional, que se constitui em espaço privilegiado de integração teórico-prática do Projeto Pedagógico do Curso, de aproximação e inserção do graduando à realidade social e pedagógica dos espaços educativos escolares e não escolares.

5- $\quad$ No curso de Pedagogia Plena - licenciatura e bacharelado - a extensão, a pesquisa e o ensino são elementos estruturantes da formação, cuja organização do trabalho pedagógico prevê ações entre o trabalho escolar e não escolar que permitem a ampla interação entre eles.

6- Processos, metodologias e postura docente que permitam a necessária dialética entre educação e experiência, garantindo um equilíbrio entre rigor intelectual e valorização dos conhecimentos já produzidos pelos estudantes em suas práticas educativas e em suas vivências socioculturais.

7- O trabalho com complexos de estudo (PISTRAK, 2008; 2009). Um Sistema de Complexos é constituído por vários centros de interesse inter-relacionados que permitem olhar e compreender diferentes áreas de conhecimento, realidades, espaços e atuação entre outros. Os complexos colocam como questão a articulação das bases da ciência com a prática social (o trabalho) e a abertura para a vida por meio de ações concretas que são referências para o debate e aprofundamento da ciência. A realidade imediata é ponto de partida para ampliar a compreensão da totalidade em que esta realidade se insere e o papel da ciência e dos conhecimentos historicamente acumulados para produzir uma transformação social.

8- Carga horária ampliada que contemple as especificidades do curso noturno e diurno para trabalhadores/as.

9- $\quad$ Deve-se ampliar a formação para as funções da escola em nível de pósgraduação gratuita e aberta a todos os licenciados/as. 
10- A constituição de uma política global de formação e valorização do magistério que contemple igualmente a formação inicial e continuada, as condições de trabalho nas escolas públicas, salários dignos e uma carreira com critérios justos e claros para o crescimento e evolução pessoal e profissional para a juventude e para os professores em exercício. (ANFOPE, 2006)

A reflexão e os pontos indicados não apresentam todos os elementos para a constituição da Pedagogia Plena; a proposta é contribuir para a fundamentação e discussão que se instala a respeito do trabalho pedagógico na formação do pedagogo, sem as dicotomias que a circundam manifestos no setor produtivo e no atual contexto brasileiro, defendendo a organização da práxis pedagógica na educação escolar e não escolar na perspectiva do trabalho como princípio educativo.

\section{Considerações finais}

Estudos e debates sobre a formação e atuação do pedagogo/a, ao longo dos últimos trinta anos, caracterizaram-se pela construção da identidade deste profissional e da ciência que lhe dá suporte epistemológico. Discutimos, neste ensaio, uma proposta de curso de Pedagogia Plena que objetive a superação de diferentes dicotomias e fragmentações, bem como busque a necessária articulação e compreensão da Pedagogia enquanto campo de conhecimento que estuda o fenômeno educativo em sua totalidade, complexidade e historicidade, e que, na formação inicial, esteja imbricada nas condições científicoculturais para produzir a teoria e prática pedagógica nos diversos campos de atuação.

Ora, as práticas educativas escolares e não escolares exercidas pelos pedagogos/as são compromissos da Pedagogia Plena. Portanto, licenciatura e bacharelado se caracterizam por serem atividades desenvolvidas pelos sujeitos em situações históricosociais definidas, imersos num determinado modo de produzir a existência material e espiritual. Esta práxis educativa, este trabalho tem uma intencionalidade ético-política; organiza-se de uma dada maneira; está implícita ou explícita numa determinada metodologia com o objetivo de atingir fins definidos; há sujeitos destinatários ou partícipes envolvidos.

Em síntese, referenciada nos estudos e documentos da Anfope, defendemos a identidade do pedagogo como profissional da educação, formado em um curso de Pedagogia Plena, licenciatura e bacharelado, para que seja capaz de analisar, compreender e lidar com as mudanças da e na vida social e suas implicações no sistema educacional, na escola e/ou fora dela. Defendemos também um curso de graduação plena com projeto 
pedagógico próprio, referenciado na Base Comum Nacional e destinado à formação de professores e profissionais para as atividades de apoio escolar; organização e gestão educacionais; e produção e difusão do conhecimento científico e tecnológico do campo educacional, comprometidos com a educação crítica de bases teóricas sólidas e voltada para a formação humana omnilateral, emancipadora.

\section{Referências}

ANFOPE. Documentos Finais dos V, VI, VII, VIII, IX, X, XI, XII e XII Encontros Nacionais da Associação Nacional pela Formação dos Profissionais da Educação. Brasília, de 1990 a 2006.

AGUIAR, Márcia Ângela da S. et al. Diretrizes curriculares do curso de pedagogia no Brasil: disputas de projetos no campo da formação do profissional da educação. Educ. Soc. [online]. 2006, vol. 27, n. 96.

BRANDÃO, Carlos Rodrigues. O Que é Educação. São Paulo. Brasiliense, 2006.

BRASIL/MEC. Lei $n^{o}$. 9.394, de 20 de dezembro de 1996. Lei de Diretrizes e Bases da Educação Nacional. Brasília, DF: 20 de dezembro de 1996.

BRASIL. Ministério de Educação. Diretrizes Curriculares Nacionais para o Curso de Graduação em Pedagogia, licenciatura. Resolução CNE/CP 1/2006. Diário Oficial da União, Brasília, 16 de maio de 2006, Seção 1, p. 11.

BRASIL. Ministério da Educação. Edital n. 4 de 10 de dezembro 1997. Convoca as Instituições de Ensino Superior a apresentar propostas para as novas Diretrizes Curriculares dos cursos superiores. Brasília: DF.

BRASIL. Conselho Nacional de Educação. Define as Diretrizes Curriculares Nacionais para a formação inicial em nível superior (cursos de licenciatura, cursos de formação pedagógica para graduados e cursos de segunda licenciatura) e para a formação continuada. Resolução CNE/CP n. 2/2015, de $1^{\circ}$ de julho de 2015. Brasília,

BRASIL. Conselho Nacional de Educação. Define as Diretrizes Curriculares Nacionais para a Formação Inicial de Professores para a Educação Básica e institui a Base Nacional Comum para a Formação Inicial de Professores da Educação Básica (BNCFormação). Resolução n. 2/2019, de 20 de dezembro de 2019.

BRASIL. Base Nacional Comum Curricular: Educação Infantil e Ensino Fundamental. Brasília: MEC/Secretaria de Educação Básica, 2017.

FRIGOTTO, Gaudêncio. O trabalho como princípio educativo no projeto de educação dos trabalhadores. In: COSTA, Hélio da; CONCEIÇÃO, Martinho. Educação Integral e 
Sistema de Reconhecimento e certificação educacional e profissional. São Paulo: Secretaria Nacional de Formação - CUT, 2005.

GRAMSCI, Antônio. Cadernos do cárcere. v. 6. Rio de Janeiro: Civilização Brasileira, 2002. Edição Carlos Nelson Coutinho.

KUENZER, Acácia Zeneida; RODRIGUES, Marli de Fátima. As diretrizes curriculares para o curso de pedagogia: uma expressão da epistemologia da prática. Olhar de Professor, Ponta Grossa, p. 35-62, 2007

MANACORDA, Mário Alighiero. Marx e a pedagogia Moderna. Tradução: Newton Ramos de Oliveira. Campinas, SP: Editora Alínea, 2010.

MARX, Karl; ENGELS, Friedrich. Textos sobre Educação e Ensino. São Paulo: Editora Moraes, 1992.

MARX, Karl. Salário, preço e lucro. In Antunes, Ricardo (ORG.) A dialética do trabalho: escritos de Marx e Engels. SP: Expressão Popular, 2004.

MARX, Karl. Salário, preço e lucro. In Antunes, Ricardo (ORG.) A dialética do trabalho: escritos de Marx e Engels. SP: Expressão Popular, 2004.

MARX, Karl; ENGELS, Friedrich. A Ideologia Alemã. Cidade: São Paulo Martins Fontes, 2007.

PISTRAK, M. Fundamentos da escola do trabalho. São Paulo: Expressão Popular, 2008. A comuna escolar. São Paulo: Expressão Popular, 2009.

SÁ, Ricardo Antunes de. Pedagogia: identidade e formação: o trabalho pedagógico nos processos escolares e não escolares. Revista Educar, Curitiba n. 16, p. 171-180, 2000.

*Katia Augusta Curado Pinheiro Cordeiro da Silva é Professora Associada - DE da Universidade de Brasília - UnB no Departamento de Administração e Planejamento - PAD da Faculdade de Educação e no Programa de Pós-graduação em Educação. Pesquisadora Produtividade do CNPq 2.

E-mail: katiacurado@unb.br

ORCID: https://orcid.org/0000-0002-9808-4577 